\title{
Efektivitas Penggunaan Kombinasi Media Audio Visual dan Booklet dibanding Media Booklet terhadap Pengetahuan Toilet Training pada Ibu yang Memiliki Balita
}

\author{
Mayasari Kurnianingsih", \\ 1. Pascasarjana Ilmu Kesehatan Masyarakat, Universitas Sebelas Maret
}

Korespondensi : mayyasarikurnia@gmail.com

\begin{abstract}
ABSTRAK
Pendahuluan:Toilet training perlu diperkenalkan secara dini untuk mengantisipasi reflek pengeluaran urin dan feses bayi pada waktu yang tepat.Di Indonesia, kegagalan toilet training dapat menyebabkan 3-5\% balita menderita ISK. Toilet training juga menyebabkan diaper rush, dan gangguan psikologi pada balita. Peran orang tua sangat berpengaruh terhadap keberhasilan toilet training. Tujuan dari penelitian ini adalah mencari media promosi kesehatan yang efektif terhadap pengetahuan toilet training pada ibu balita.

Metode: Jenis penelitian ini adalah quasi eksperimendengan rancangan penelitian pretest and posttest with control group design. Teknik pengambilan sampel adalah simple random sampling. Jumlah sampel dalam penelitian ini 66 orang dibagi menjadi dua kelompok, kelompok perlakuan (audio visual disertai booklet) dan kelompok kontrol (booklet). Alat ukur penelitian menggunakan kuisioner. Paired sampel t-test dan independent sampel t-test digunakan untuk menganalisis data dalam penelitian ini.

Hasil: Terjadi peningkatan rerata pengetahuan toilet training setelah diberi perlakuan pada kelompok audio visual disertai booklet sebesar 9,68 dan $p_{-}$value 0,00 serta pada kelompok kontrol booklet dengan rerata 8,85 dan p_value $0,00(\mathrm{p}<0,05)$. Selain itu, terdapat peningkatan skor rerata pengetahuan yang lebih tinggi pada kelompok audio visual disertai booklet dibandingkan dengan kelompok booklet $(\mathrm{p}=0,031)$.

Kesimpulan: Promosi kesehatan toilet training pada ibu balita di Posyandu Karanganyar dengan media audio visual disertai booklet lebih efektif dibandingkan dengan media booklet.
\end{abstract}

Kata kunci:booklet; media audio visual; toilet training

\begin{abstract}
Introduction:Toilet training is one of the main tasks of child in toddler age. Toilet training need to be introduced early to anticipate an eject reflex of infant urine and feces at the right time. To young children in Singapore, there are $15 \%$ who experienced failure of toilet training. In Indonesia, the failure of toilet training can lead to 3-5\% of children under five years old suffering from a UTI. Toilet training also cause diaper rush and a psychological disorderto a toddler. The role of parents is very influential in the success of toilet training. One of the efforts to increase mother knowledge is through promotion of health about toilet training. This research is to compare the media that more effective to increase knowledge about toilet training to mother in Integrated Health Post. The purpose of this research is looking for the health promotionmedia that is effective to explain knowledge about toilet training in children under five years old.

Methods:Thisresearch used experiment quasi and pretest and posttest researchdesign with control group design. Sampling techniqueused simple random sampling. Samples of this research were 66 people, divided into two groups, the treatment group (audiovisual and booklet) and the control group(booklet). Measuringinstrument in this
\end{abstract}


research used questionnaire. Paired sample t-test and independent sample t-test was used to analyze data in this research.

Results:There was mean increment in knowledge of toilet training, after being giventreatment with audio visual and booklet was 9,68 and p_value 0,00. The control group that were given booklet was 8,85 and p_value 0, 00 (p<0,05). In addition, there was an increment in knowledge mean score that was higher in the audio visual and booklet groupthan in the booklet group $(p=0,031)$.

Conclusion:Health promotion of toilet training tomother in Karanganyar Integrated Health Post with audio visual and booklet media is more effective than with booklet media.

Keyword: booklet; audio visual media; toilet training

\section{PENDAHULUAN}

Infeksi Saluran Kemih

(ISK) merupakan infeksi saluran kencing yang serius dan penting pada anak. Di Indonesia, dari sekitar 22.000.000 balita angka kejadian ISK sekitar 660.000-1.100.000 pada perempuan dan 220.000 pada laki-laki sampai usia 5 tahun. ISK ini lebih sering menjadi masalah selama masa bayi dan periode toilet training. Gejala ISK pada anak tidak khas. Demam ( $\geq 38$ C) tanpa disertai gejala lain merupakan gejala ISK yang sering muncul pada anak usia 2 bulan hingga 2 tahun dan faktor risiko utama terjadinya ISK adalah stasis. ${ }^{1,2}$

Berdasarkan data dari Dinas Kesehatan Provinsi Yogyakarta pada bulan Mei 2016 didapatkan hasil angka kejadian Penyakit Sistem Kemih tertinggi tahun 2014 di Kabupaten Bantul yaitu 123 kejadian pada balita laki-laki usia 0-59 bulan dan 107 kejadian pada balita perempuan usia 0-59 bulan, sedangkan angka kejadiannyayang terendahterjadi di Kulon Progo yaitu sebanyak 5 kejadian pada balita laki-laki usia 0-59 bulan dan 2 kejadian pada balita perempuan usia 0-59 bulan. Data Dinas Kesehatan Kabupaten Bantul pada bulan Juni 2016 menunjukkan bahwa kejadian Penyakit Sistem Kemih tahun 2015 yang tertinggi yaitu di kecamatan Sanden dengan 433 kejadian dan terendah di kecamatan Piyungan dengan 1 kejadian. $^{3}$

Toilet training adalah suatu proses pengajaran serta usaha melatih kemampuan anak untuk mengontrol buang air kecil (BAK) dan buang air besar (BAB) secara benar dan teratur. Tidak terdapat patokan waktu yang ideal untuk memulai toilet training. Patokan utamanya adalah kesiapan fisik dan mental anak serta kesiapan dari orangtua itu sendiri. Ada beberapa tanda penting terkait keseiapa toilet training, yaitu kebiasaan buang air yang jarang pada anak, anak mengerti perintah dan penjelasan sederhana, anak mulai meniru kebiasaan orang dewasa di kamar mandi, dan anak tidak suka saat dirinya basah atau kotor. ${ }^{4}$

Melalui toilet training anak akan belajar bagaimana mereka mengendalikan keinginan untuk buang air kecil dan selanjutnya mereka menjadi terbiasa menggunakan toilet secara mandiri. ${ }^{5} \mathrm{Di}$ Singapura didapatkan $15 \%$ anak tetap mengompol diusia 5 tahun, sedangkan di Inggris masih ditemukan kasus anak dengan kebiasaan $\mathrm{BAB}$ sembarangan pada usia 7 tahun, hal ini kemungkinan disebabkan kegagalan toilet training pada usia toddler. ${ }^{6}$ Hasil penelitian lain menyebutkan bahwa $90 \%$ dari anak usia 2-3 tahun berhasil diajarkan melakukan toilet training dan $80 \%$ dari anakanak mendapat kesuksesan tidak mengompol dimalam hari antara usia 3-4 tahun. ${ }^{7}$ Bukti tersebut tersebut menggambarkan bahwa toilet training pada anak toddler menjadi hal yang penting dilakukan.

Hal-hal yang paling umum terjadi dalam kegagalan toilet training diantaranya adalah adanya perlakuan atau aturan yang ketat dari orangtua kepada anaknya dapat 
mengganggu kepribadian anak dan cenderung bersikap keras kepala bahkan kikir, seperti orangtua sering memarahi anak pada saat $\mathrm{BAB}$ atau BAK atau bahkan melarang $\mathrm{BAB}$ atau BAK saat bepergian. Di sisi lain, apabila orangtua juga santai dalam memberikan aturan toilet training, maka anak dapat mengalami kepribadian ekspresif, seperti anak menjadi lebih tega, cenderung ceroboh, suka membuat gara-gara, emosional, dan seenaknya dalam melakukan kegiatan seharihari. ${ }^{8}$

Oleh karena itu, peran orang tua disini sangat dibutuhkan demi tercapainya toilet trainingyang berhasil. Peranan orangtua dalam mendidik anak sangat besar. Salah satunya mengajarkan anak tentang toilet training. Namun banyak orangtua hanya sekedar mengajarkan saja. Perlu dilakukan pengajaran pada orang tua balita, bagaimana melatih toilet training yang benar kepada anak. Promosi kesehatan sekiranya akan membantu dalam pembelajaran dan meningkatkan pengetahuan ibu.

Promosi kesehatan dilakukan sesuai Visi Pembangunan Kesehatan Indonesia yaitu meningkatnya kemampuan masyarakat untuk memelihara dan meningkatkan derajat kesehatannya (fisik, mental dan sosial) sehingga produktif secara ekonomi maupun sosial.

Berdasarkan data yang diperoleh dari Dinas Kesehatan Provinsi Yogyakarta pada bulan Juni 2016 di dapatkan hasil bahwa jumlah kegiatan promosi kesehatan tertinggi tahun 2015 adalah Kabupaten Kulon Progo dengan jumlah 4061 kegiatan, dan yang terendah adalah Kabupaten Bantul dengan jumlah 18 kegiatan. Data lain dari Dinas Kesehatan Provinsi Yogyakarta menunjukkan bahwa jumlah posyandu aktif tahun 2015 yang tertinggi adalah Kabupaten Kulon Progo dengan persentase $90,11 \%$, dan terendah adalah Kabupaten Bantul dengan persentase $65,99 \% .^{3}$
Selain itu data dari Dinas Kesehatan Kabupaten Bantul pada bulan Juni 2016 nenunjukkan bahwa jumlah kegiatan promosi kesehatan di posyandu tentang balita pada tahun 2014 adalah 17 kegiatan, dan pada tahun 2015 adalah 18 kegiatan. ${ }^{9}$ Data dari Puskesmas Sanden pada Bulan Juni 2016 menunjukkan bahwa di Kecamatan Sanden terdapat 63 Posyandu Balita. Dari 63 posyandu tersebut, posyandu yang memiliki jumlah balita tertinggi adalah posyandu Karanganyar yaitu dengan data terakhir tahun 2016 sebanyak 71 balita dan terendah posyandu Gokerten dengan jumlah 11 balita. $^{10}$

Dalam promosi kesehatan dibutuhkan media yang mempunyai peranan penting sebagai alat bantu untuk menciptakan keberhasilan dalam memberikan promosi kesehatan. Sejauh ini leaflet digunakan sebagai media pembelajaran dalam promosi kesehatan dan dibagikan setiap bulannya atau setiap diadakannya promosi kesehatan, namun pembagian leaflet hanya pasif serta tidak ada penjelasan lebih lajut mengenai isi leaflet. Leaflet yang dibagikan juga tidak pernah berisi materi tentang toilet trainning, sebagian besar membahas tentang gizi, kesehatan ibu, dan bayi. Pada Buku KIA yang digunakan ibu untuk mengetahui perkembangan kesehatan ibu dan bayi sebagai sumber informasi juga tidak terdapat materi atau informasi mengenai toilet training. Sehingga peneliti tertarik untuk mengangkat kasus ini, karena toilet training sangat penting namun sumber informasi yang di dapatkan sangan kurang.

Dalam penelitian ini, dari berbagai media, peneliti memilih menggunakan media audio visual. Kelebihan media audio visual ini dapat mengubah materi ajar yang berupa teoritis menjadi kegiatan interaktif yang menunjukkan prosedur pelaksanaan dari materi. ${ }^{11}$ Media audio visual juga dapat menyampaikan informasi tertentu lebih baik dibandingkan dengan media yang berbentuk tulisan dan media audio visual memiliki efek motivasi dalam proses pembelajaran. ${ }^{12,13}$ 
Peneliti juga menggunakan media lain sebagai pembanding, yaitu media visual. Media visual merupakan media sederhana yang mudah dibuat dan digunakan. ${ }^{14}$ Media ini menggunakan visualisasi dalam memberikan informasi. Contoh medianya adalah poster, papan tulis, booklet, model, gambar, dan sebagainya. Dari semua media visual, booklet paling sering digunakan para pengajar untuk menyampaikan materi. Booklet dapat dibuat dengan mudah yaitu dengan menggabungkan gambar dan tulisan yang berisi informasi lengkap dalam buku berukuran $5 \times 7$ inci sehingga mudah dibawa. ${ }^{15,16}$

Dari hasil studi pendahuluan yang dilakukan peneliti pada tanggal 2 September 2016 melalui wawancara kepada sepuluh ibu di Posyandu Karanganyar, di dapatkan hasil yaitu tiga dari sepuluh ibu pernah mendengar istilah toilet training dan sembilan dari sepuluh ibu belum mengetahui tentang toilet training. Alasan lain posyandu ini dipilih karena belum pernah ada yang melakukan penelitian, belum pernah dilakukan promosi kesehatan tentang toilet training dan letaknya juga di pedesaan. Tempat tinggal seseorang juga sangat mempengaruhi perilaku seseorang terhadap kesehatan, bagi yang tinggal di daerah pedesaan atau pedalaman akses untuk memperoleh informasi masih kurang jika dibandingkan daerah kota. ${ }^{17}$

Oleh karena itu, penelitian ini dilakukan di Posyandu Karanganyar untuk mengajarkan orang tua balita agar dapat menerapkan toilet training kepada anaknya dan juga pengisi kuesioner adalah orang tua balita untuk mengetahui skor pengetahuan ibu tentang toileting anaknya.

\section{METODE PENELITIAN}

Desain penelitian ini adalah studi quasi eksperimental dengan menggunakan rancangan penelitian pretest-posttestwith control grup design. Tujuan dari rancangan pretest-posttest with control grup design bertujuan untuk mengetahui pengaruh yang timbul karena adanya perlakukan tertentu atau eksperimen.

Penelitian dilakukan di satu Posyandu wilayah Dusun Karanganyar Sanden Bantul. Populasi pada penelitian ini adalah seluruh ibu yang memiliki balita di Posyandu Karanganyar yang hadir saat penelitian.

Teknik pengambilan sampel adalah probability sampling dengan simple random sampling. Besar sampel minimal yang dibutuhkan masing-masing kelompok adalah 31 responden. Dengan demikian jumlah total sampel yang dibutuhkan minimal 62 responden.

Variabel bebas dalam penelitian ini adalah penggunaan media audio visual disertai booklet dan booklet media dalam memberikan promosi kesehatan dan variabel terikatnya adalah Pengetahuan ibu tentang toilet training.

Peneliti menggunakan instrumen penelitian berupa instrumen kuisioner menggunakan dengan nilai Benar $=1$ dan nilai salah $=0$. Pertanyaan berjumlah 13 item yang telah di uji validitas dengan hasil $r$ hitung positif $>r$ tabel $(r$ tabel : 0,4227) dan realibilitas dengan hasil cronbach's alpha $0,925>0,7$.

Pengumpulan data dilakukan dengan melakukan pretest, pemberian promosi kesehatan pada masing-masing grup perlakuan dan grup kontrol dan melakukan posttest.Pengujian hipotesis dilakukan dengan Uji Paired T-test untuk membandingkan antara rerata skor pengetahuan tentang Toilet Training sebelum dan sesudah diberikan media pembelajaran audio visual (video) disertai booklet dan media pembelajaran booklet serta Uji Independent Sample T-test yaitu uji komparatif atau uji beda untuk mengetahui perbedaan antara nilai selisih rerata skor pengetahuan sebelum dan sesudah diberikan media pembelajaran audio visual (video) disertai booklet dan media pembelajaran booklet. 


\section{HASIL PENELITIAN}

\section{A. Analisis Univariat}

\section{Karakteristik Responden}

Responden total pada penelitian ini berjumlah 66 ibu yang memiliki balita di Posyandu Karanganyar. Kelompok yang diberikan promosi kesehatan menggunakan media audio visual disertai booklet sebanyak 33 ibu dan kelompok yang diberikan promosi kesehatan dengan menggunakan media booklet sebanyak
33 ibu. Dari penjabaran karakteristik ibu di dapatkan mayoritas berpendidikan SMA, berada pada usia 26-35 tahun, memiliki paritas 1-2 anak dan memiliki pekerjaan sebagai IRT. Hasil uji homogenitaskedua kelompok yaitu kelompok perlakuan dan kontrol adalah setara (homogen) sehingga telah memenuhi syarat penelitian eksperimen yaitu $\geq 2$ variabel harus homogen $(>0,05)$.

Tabel 4.1 Karakteristik Responden Pada Dua Kelompok

\begin{tabular}{|c|c|c|c|c|c|c|c|}
\hline \multicolumn{2}{|c|}{ Karakteristik } & \multicolumn{2}{|c|}{$\begin{array}{c}\text { Audio } \\
\text { Visual+Booklet } \\
\text { (Perlakuan) }\end{array}$} & \multicolumn{4}{|c|}{$\begin{array}{c}\text { Booklet } \\
\text { (kontrol) }\end{array}$} \\
\hline & & $\mathrm{F}$ & $\%$ & Sig. & $\mathrm{F}$ & $\%$ & Sig. \\
\hline \multirow{4}{*}{ Pendidikan } & SD & 2 & 6.1 & \multirow{4}{*}{0.166} & 2 & 6.1 & \multirow{4}{*}{0.000} \\
\hline & SMP & 6 & 18.2 & & 6 & 18.2 & \\
\hline & SMA & 22 & 66.7 & & 22 & 66.7 & \\
\hline & Sarjana & 3 & 9.1 & & 3 & 9.1 & \\
\hline \multirow{4}{*}{ Usia } & 15-25 Tahun & 8 & 24.2 & \multirow{4}{*}{0.209} & 4 & 12.1 & \multirow{4}{*}{0.106} \\
\hline & 26-35 Tahun & & & & & & \\
\hline & 36-50 Tahun & 18 & 54.5 & & 19 & 57.6 & \\
\hline & & 7 & 21.2 & & 10 & 30.3 & \\
\hline \multirow[b]{2}{*}{ Paritas } & 1-2 Anak & 23 & 69.7 & \multirow[b]{2}{*}{0.204} & 27 & 81.8 & \multirow[b]{2}{*}{0.692} \\
\hline & $>2$ Anak & 10 & 30.3 & & 6 & $\begin{array}{l}01.0 \\
18.2\end{array}$ & \\
\hline \multirow{4}{*}{ Pekerjaan } & IRT & 29 & 87.9 & \multirow{4}{*}{0.073} & 25 & 75.8 & \multirow{4}{*}{0.149} \\
\hline & Pegawai & 0 & 0.0 & & 1 & 3.0 & \\
\hline & Wiraswasta & 2 & 6.1 & & 4 & 12.1 & \\
\hline & Buruh & 2 & 6.1 & & 3 & 9.1 & \\
\hline
\end{tabular}

Sumber : data primer 2017

\section{Uji Normalitas}

Tabel 4.2 Deskripsi Data Uji Normalitas

\begin{tabular}{cccc}
\hline Kelompok Sampel & Kolmogorov-Smirnov Z & $\begin{array}{c}\text { Asymp. } \\
\text { Sig }\end{array}$ & Keterangan \\
\hline Pemberian Audio Visual dan & 1.239 & 0.093 & Data Normal \\
$\begin{array}{c}\text { Booklet } \\
\text { Pemberian Booklet }\end{array}$ & 0.949 & 0.328 & Data Normal \\
\hline Sumber : data primer 2017 & & &
\end{tabular}

Data dikatakan berdistribusi normal jika diketahui nilai asymp.sig > 0,05. Sehingga dapat disimpulkan dari tabel di atasbahwa pemberian audio visual disertai booklet dan pemberian booklet data berdistribusi normal karena nilai asymp.sig $>0,05$.

\section{B. Analisis Bivariat}

1. Perbedaan Skor Pengetahuan Ibu Sebelum dan Sesudah Diberikan Media Audio Visual disertai Booklet dan Media Booklet

Hasil uji paired t-test pada kelompok audio visual disertai booklet 13,692 dan pada kelompok booklet 9,639. P value pada kelompok audio visual disertai booklet dan 
Kurnianingsih, Efektivitas Penggunaan Media Audio Visual Disertai Booklet Dibandingkan Media Booklet Terhadap Pengetahuan Toilet Training Pada Ibu Yang Memiliki Balita Di Posyandu Karanganyar Sanden Bantul.

booklet menunjukkan 0,000 ( $\mathrm{p}<0,05)$. Karena nilai $\mathrm{p}<0,05$ secara statistik terdapat perbedaanyang bermakna sebelum dan sesudah pada kelompok audio visual disertai booklet dan booklet. Karena ada perbedaan pretest dan posttest 9,68 dan 8,85 , secara klinis terdapat perbedaan sebelum dan sesudah pada kelompok audio visual disertai booklet dan booklet.

Tabel 4.3Perbedaan Skor Pengetahuan Ibu Sebelum dan Sesudah Diberikan Media Audio Visual disertai Booklet dan Media Booklet.

\begin{tabular}{|c|c|c|c|c|c|c|c|c|}
\hline \multirow{3}{*}{ Variabel } & \multicolumn{4}{|c|}{ Pengetahuan } & \multirow{2}{*}{\multicolumn{2}{|c|}{$\Delta$}} & \multirow{3}{*}{$\begin{array}{c}\text { Uji } \\
\text { Statistik } \\
\text { Paired } \\
\text { t-test }\end{array}$} & \multirow{3}{*}{$\mathrm{P}$ value } \\
\hline & \multicolumn{2}{|c|}{ Pretest } & \multicolumn{2}{|c|}{ Posttest } & & & & \\
\hline & Mean & SD & Mean & SD & Mean & SD & & \\
\hline $\begin{array}{l}\text { Kelompok } \\
\text { Audio } \\
\text { Visualdisertai } \\
\text { Booklet }\end{array}$ & 8,33 & 1,614 & 11,03 & 1,489 & 9,68 & 1,132 & 13,692 & 0,000 \\
\hline $\begin{array}{l}\text { Kelompok } \\
\text { Booklet }\end{array}$ & 7,48 & 2,017 & 10,21 & 1,763 & 8,85 & 1,625 & 9,639 & 0,000 \\
\hline
\end{tabular}

2. Perbandingan Pengetahuan Ibu Setelah Dilakukan Promosi Kesehatan dengan Menggunakan Media Audio Visual disertai Booklet Dibandingkan Media Booklet.

P-value menunjukkan $0,031<0,05$. Hasil tersebut membuktikan setelah dilakukan intervensi berupa promosi kesehatan hipotesis
H0 ditolak dan Ha diterima, artinya terdapat peningkatan pengetahuantoilet training dengan media audio visual disertai booklet lebih tinggi dibandingkan dengan media booklet pada ibu di Posyandu Karanganyar dengan perbedaan rerata 0,833 dan SD 0,382.

Tabel 4.4 Perbandingan Pengetahuan Ibu Setelah Dilakukan Promosi Kesehatan dengan Menggunakan Media Audio Visual disertai Booklet Dibandingkan Media Booklet.

\begin{tabular}{|c|c|c|c|c|c|c|}
\hline \multirow{2}{*}{ Variabel } & \multicolumn{2}{|c|}{$\Delta$} & \multicolumn{2}{|c|}{ Perbandingan $\Delta$} & \multirow{2}{*}{$\begin{array}{c}\text { Uji Statistik } \\
\text { Independent } \\
\text { T-test }\end{array}$} & \multirow{2}{*}{$P$ value } \\
\hline & Mean & SD & Mean & SD & & \\
\hline $\begin{array}{l}\text { Kelompok } \\
\text { Audio } \\
\text { Visualdisertai } \\
\text { Booklet } \\
\text { Kelompok } \\
\text { Booklet }\end{array}$ & 8,85 & 1,625 & 0,833 & 0,382 & 2,180 & 0,031 \\
\hline
\end{tabular}

Sumber : Data Primer, 2017

\section{PEMBAHASAN}

Karakteristik kedua kelompok tersebut sama, sehingga faktor-faktor yang diketahui dapat mempengaruhi pengetahuan ibu dapat dikendalikan. Faktor-faktor tersebut diantaranya adalah pendidikan karena pendidikan dapat mempengaruhi cara pandang seseorang terhadap informasi baru yang diterimanya, usia karena usia mempengaruhi daya tangkap dan pola pikir seseorang, pengalaman atau paritas karena seorang ibu yang pernah memiliki anak atau melahirkan lebih dari satu kali mempunyai pengalaman lebih dari pada seorang ibu yang baru memiliki anak pertama, serta pekerjaan karena lingkungan pekerjaan dapat menjadikan 
seseorang memperoleh pengalaman dan pengetahuan baik secara langsung maupun tidak langsung. ${ }^{18}$ Dan dari uji homogenitas yang dilakukan dengan anova didapatkan hasil nilai sig. > 0,05. Sehingga hal yang membedakan pada kedua kelompok tersebut adalah media yang digunakan untuk promosi kesehatan tentang toilet training. Berdasarkan hasil penelitian diketahui bahwa efektivitas penggunaan media audio visual disertai booklet terhadap toilet training pada ibu yang memiliki balita di Posyandu Karangayar dapat terlihat dari uji statistik paired t-test antara sebelum dan sesudah pada kelompok sampel yaitu diperoleh hasil $p$ value $(0,000)<0,05$ maka dapat disimpulkan ada perbedaan yang signifikan sebelum dan sesudah pada kelompok sampel penggunaan media audio visual disertai booklet.

Media yang dapat digunakan untuk memberikan promosi kesehatan selain media visual adalah media audio visual. Audio visual dengan penyampaian dan tampilan persuasif menjadikan media komunikasi sangat bermanfaat bagi peningkatan pengetahuan dan perilaku hidup sehat. Media audio visual ini mampu menstimulasi indera pendengaran dan penglihatan saat proses penyampaian bahan promosi kesehatan. ${ }^{6}$ Media ini mempunyai peranan penting sebagai alat bantu untuk menciptakan keberhasilan dalam memberikan promosi kesehatan. Media audio visual ini dapat mengubah materi ajar yang berupa teoritis menjadi kegiatan interaktif yang menunjukkan prosedur pelaksanaan dari materi. Media tersebut diakatakan berhasil jika dapat meningkatkan atau mencapai tujuan pembelajaran. ${ }^{19}$

Hasil tersebut mendukung penelitian Luh Putu Karsi Ekayani (2015) bahwa terdapat peningkatan yang signifikan pada pengetahuan toilet training setelah mendapatkan penyuluhan dengan menggunakan media audio visual. ${ }^{20}$
Berdasarkan hasil penelitian ini juga diketahui bahwa efektivitas penggunaan media bookletterhadap pengetahuan toilet training pada ibu yang memiliki balita di Posyandu Karangayar dapat terlihat dari uji statistik paired t-test antara sebelum dan sesudah pada kelompok sampel diperoleh hasil $p$ value $(0,000)<0,05$ maka dapat disimpulkan ada perbedaan yang signifikan sebelum dan sesudah pada kelompok sampel penggunaan media booklet.

Booklet adalah media berbentuk buku kecil yang berisi tulisan atau gambar yang memiliki keunggulan dibandingkan media visual yang lain. Booklet juga paling sering digunakan para pengajar. Booklet dapat dibuat dengan mudah yaitu dengan menggabungkan gambar dan tulisan yang berisi informasi lengkap dalam buku berukuran $5 \mathrm{X} 7$ inci sehingga mudah dibawa. ${ }^{11}$

Penelitian ini sejalan dengan penelitian yang dilakukan oleh Ammelda (2012), menyatakan bahwa mudahnya seseorang dalam mendapatkan informasi dan pengetahuan tentang toilet training membuat seseorang lebih siap menghadapi pentingnya toilet dalam kehidupan sehari-hari dan sumber dari pengetahuan itu didapatkan dengan mudah melalui gambar dan penjelasan (media booklet). ${ }^{14}$

Hasil pretest dan posttest kelompok media audio visual disertai booklet dan media booklet pada ibu yang memiliki balita di Posyandu Karanganyar menunjukkan bahwa didapatkan nilai $\mathrm{p}<0,05$ kesimpulannya secara statistik terdapat perbedaan rerata nilai pengetahuan antara kelompok media audio visual disertai booklet dan media booklet. $P$ value menunjukkan $0,031<0,05$. Hasil tersebut membuktikan setelah dilakukan intervensi berupa promosi kesehatan tentang toilet training, hipotesis $\mathrm{H} 0$ ditolak dan $\mathrm{Ha}$ diterima, artinya terdapat perbedaan rerata pengetahuan toilet training dengan media audio visual disertai booklet dan booklet terhadap pengetahuan toilet training pada ibu 
yang memiliki balita di Posyandu Karanganyar.

Penelitian ini sejalan dengan penelitian Mujahidatul (2014) yang menjelaskan bahwa promosi kesehatan sangat berpengaruh meningkatkan pengetahuan ibu tentang toilet training. Melalui promosi kesehatan, dapat menyampaikan informasi kesehatan dan memotivasi untuk berlaku sehat. ${ }^{21}$ Serta penelitian yang dilakukan oleh Maya Angela (2015) yang menyatakan bahwa media audio visual (video) lebih cepat dalam menyampaikan informasi karena media video menyampaikan pesan lewat audio dan visual sehingga seseorang lebih paham yang diajarkan melalaui media video dan didukung dengan media booklet, seseorang lebih mudah untuk membawa informasi kemana-mana karena bentuknya yang praktis dan dapat membagikan pengetahuan terhadap orang lain yang masih kurang tentang toilet training. ${ }^{17}$

Hasil penelitian ini menunjukkan promosi kesehatan dengan media audio visual disertai booklet merupakan media yang lebih efektif untukmeningkatkan pengetahuan toilet training pada ibu yang memiliki balita.

Promosi kesehatan dengan media audio visual disertai booklet terhadap pengetahuan toilet training menunjukkan nilai posttest lebih tinggi dari pretest, dengan demikian media tersebut mampu meningkatkan pengetahuan toilet training pada ibu, sehingga dapat diterapkan untuk meningkatkan pengetahuan kesehatan khususnya pengetahuan toilet training pada ibu yang memiliki balita.

Media audio visual (video) dan booklet sangat berpengaruh dalam memberikan pembelajaran tentang kesehatan seperti pembelajaran tentang toilet training. Karena media audio visual dan didukung dengan media booklet akan lebih mempermudah dalam menyampaikan pembelajaran toilet training tersebut. ${ }^{22}$

Berdasarkan hasil penelitian serta teori yang berhubungan dengan promosi kesehatan dalam peningkatan pengetahuan toilet training ibu, dapat disimpulkan bahwa adanya pengaruh pemberian promosi kesehatan dapat meningkatkan pengetahuan ibu, dalam hal ini adalah pengetahuan toilet training. Hasil penelitian ini membuktikan bahwa setelah dilakukan intervensi promosi kesehatan dengan media audio visual disertai booklet lebih efektif dibandingkan media booklet terhadap pengetahuan toilet training pada ibu yang memiliki balita di Posyandu Karanganyar.

Keberhasilan suatu program atau kegiatan promosi kesehatan terlihat dari adanya peningkatan hasil pembelajaran yang dilaksanakan, sehingga kesesuaian peningkatan hasil pada kelompok perlakuan dan kelompok kontrol telah sesuai dengan teori yang ada

\section{KESIMPULAN DAN SARAN}

\section{A. Kesimpulan}

1. Peningkatan yang bermakna terjadi pada pengetahuan ibu tentang toilet training setelahdiberikan promosi kesehatan dengan media audio visual disertai booklet maupun media booklet.

2. Perbedaan skor berubah secara significant antara kelompok perlakuan (audio visual disertai booklet) dan kelompok kontrol (booklet).

3. Dari kedua media tersebut, yang paling efektif adalah media audio visual disertai booklet dengan dibandingkan media booklet.

\section{B. Saran}

1. Bagi Tenaga Kesehatan Khususnya

Bidan di Puskesmas

Berdasarkan penelitian bahwa edukasi pada ibu balita lebih efektif menggunakan media audio visual disertai booklet, sehingga bisa diterapkan sebagai salah satu media baru yang efektif dalam proses promosi kesehatan di Puskesmas.

2. Bagi Kader Posyandu 
Karena kader sebagai perpanjangan tangan bidan, maka diharapkan kader kesehatan posyandu diberikan pelatihan menggunakan media audio visual disertai booklet atau media yang mirip dari segi fungsi sehingga dapat melakukan tugasnya sebagai pendamping ibu balita untuk menyampaikan informasi kesehatan khususnya toilet training.

\section{Bagi Penelitian Lanjut}

Perlu adanya pengembangan selanjutnya dari media ini agar pesan yang ingin disampaikan dapat lebih mudah dipahami dan sesuai dengan perkembangan tekhnologi dan kesehatan.

\section{UCAPAN TERIMAKASIH}

Kami ucapkan terimakasih kepada pihak posyandu yang telah membantu jalannya penelitian dan ibu yang memiliki balita yang telah berpartisipasi dan bersedia menjadi subjek penelitian.

\section{DAFTAR PUSTAKA}

1. AAP (American Academy of Periodontology). 1999. International Workshop for a Classification of Periodontology Diseases and Conditions. Papers. Oak Brook. Illionois. October 30November 2. Ann Periodontal 1999. 4:i, 1112.

2. Fahimzad, A., Taherian, M., Dalirani, R., Shamsiri, A. 2010. Diaper type as a risk factor in urinary tract infection of children. Iran J Pediatr. Mar; 20:97-100.

3. Dinas Kesehatan Yogyakarta. 2016. Profil Kesehatan Provinsi Yogyakarta. Yogyakarta.

4. Wong. 2008. Buku Ajar Keperawatan Pediatrik WONG. alih bahasa: Hartono. Jakarta: EGC.

5. Whaley dan Wong, 2000. Buku Ajar Keperawatan Pediatrik. edisi 2 Jakarta: EGC.

6. Irawan. 2003. Pendekatan Mutu dan Kepuasan Pelanggan dalam Pelayanan Kesehatan. Program Pasca Sarjana UNHAS.
7. Brazelton T. 8., Dr. 2003. Born to be Genius. Jakarta: Prestasi Pustaka.

8. Hidayat, Aziz Alimul. 2005. Pengantar Ilmu Keperawatan Anak. Jakarta: Salemba Medika.

9. Moreno, R., \& Ortegano-Layne, L. 2008. Do classroom exemplars promote the application of principles in teacher education. A comparison of videos, animation, and naratives. Education Tech Research Dev: Springer. 56. P. 449-465.

10. Jha B N, G D Sharma \& A K Shukla. 2008. Effect of ectomycorrhizal development on growth in pine seedlings. Journal of Plant Science3(1): 77-84. [ISSN: 1816-4951, Academic journals, USA].

11. Duran, E. 2006. Teaching English Learners in Inclusive Classrooms. Charles $\mathrm{C}$ Thomas Publisher. Illinois. hal 73.

12. Edelman C.L., \&Mandle,C.L. 2006. Health Promotion Throughout The Life Span, seventh edition. St.Louis, Missouri: Mosby.

13. Mokodongan $\mathbf{M}$, wantania J dan Wagey. Hubungan Tingkat Pengetahuan Tentang Keputihan dengan Perilaku Pencegahan Keputihan Pada Remaja Putri. [Jurnal eClinic (eCI)]. 3(1). Januari-April 2015.

14. Ammelda 2012. Pengaruh Modeling Media Video dan Gambar Terhadap Peningkatan Kemampuan Toilet Training Pada Anak Toddler. Yogyakarta: Universitas Gadjah Mada

15. Rosiana Wahyu Probowati. 2014. Pengaruh Pendidikan Kesehatan Tentang Toilet Training Anak Usia 1-3 Tahun Terhadap Pengetahuan Ibu Di Desa Sambon Banyudono Boyolali. Yogyakarta: Universitas Gadjah Mada.

16. Devi Septianingrum. 2015. Pengaruh Pendidikan Kesehatan Cuci Tangan dengan Media Audio visual dan Leaflet terhadap Pengetahuan Cuci Tangan Anak SD di Kota Yogyakarta. Yogyakarta: Universitas Gadjah Mada

17. Maya Angela. 2015. Perbandingan Perubahan Anak Usia 10-12 tahun pada Promosi Kesehatan Gigi dan Mulut antara Metode Ceramah dengan Media poster dan Metode Diskusi dengan Media Booklet dan Audio visual. Yogyakarta: Universitas Gadjah Mada.

18. Srimiyati. 2014. Pengaruh Pendidikan Menggunakan Booklet Terhadap Pengetahuan dan Gejala Kecemasan Wanita Menopause (Tesis). Yogyakarta: Magister Keperawatan UGM. 
Kurnianingsih, Efektivitas Penggunaan Media Audio Visual Disertai Booklet Dibandingkan Media Booklet Terhadap Pengetahuan Toilet Training Pada Ibu Yang Memiliki Balita Di Posyandu Karanganyar Sanden Bantul.

19. Hujair AH. Sanaky. 2011. Media Pembelajaran Buku Pegangan Guru dan Dosen. Yogyakarta: Kaukaba.

20. Ekayani, Luh Putu Karsi. 2015. Efektivitas Penyuluhan dengan Audio Visual Terhadap Keberhasilan Toilet Training Pada Anak Umur 2-3 Tahun. Banjar: FK Udayana.

21. Mujahidatul, Beny. 2014. Public Health Journal. Universitas Negeri Semarang.

22. Indanah, dkk. 2014. Pemakaian Diapers Dan Efek Terhadap Kemampuan Toilet Training Pada Anak Usia Toddler. STIKES Muhammadiyah Kudus: Jawa Tengah. JIKK Vol. 5. No. 3 : 62. 